\title{
COVID-19 and Cardiovascular Complications: An Updated Review
}

\author{
Januar Wibawa Martha* \\ Department of Cardiology and Vascular Medicine, Faculty of Medicine, Universitas Padjadjaran, Rumah Sakit Umum Pusat \\ Hasan Sadikin, Bandung, Indonesia
}

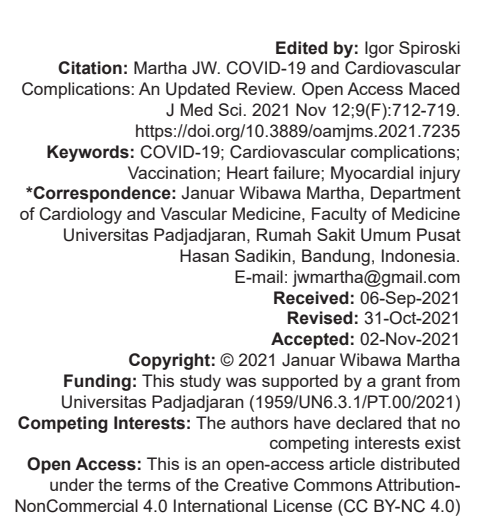

Abstract

Coronavirus disease 2019 (COVID-19) has become a global pandemic. Patients with pre-existing comorbidities such as hypertension, diabetes, and cardiovascular disease (CVD) are associated with greater severity and mortality. COVID-19 can cause cardiovascular complications, including myocardial injury, myocarditis, heart failure, acute coronary syndrome (ACS), and coagulation abnormalities. Possible pathophysiology and molecular pathways driving these disease processes are cytokine release syndrome (CRS), renin-angiotensin-aldosterone system (RAAS) system dysregulation, plaque destabilization, and coagulation disorders. Myocarditis is one concern among persons who received mRNA-based COVID-19 vaccines. Several cardiovascular complications are possibly caused by COVID-19 treatments, such as QT interval prolongation, arrhythmia, and hypotension. Due to increasingly recognized CVD damage in COVID-19, we need to understand about COVID-19 related to cardiovascular complications and treatment strategies.

\section{Introduction}

Coronavirus disease 2019 (COVID-19) causes severe acute respiratory syndrome coronavirus 2 (SARS-CoV-2) was first reported to the WHO as pneumonia of unknown cause in Wuhan, China, on December 31, 2019. It spreads quickly and becomes a global pandemic [1].

COVID-19 patients with cardiovascular disease (CVD) have higher mortality, and the severity of COVID-19 disease correlates with cardiovascular manifestations. It is critical to understand the interaction between COVID-19 and CVD [2].

COVID-19 uses the angiotensin-converting enzyme-2 (ACE-2) protein for ligand-binding before entering the cell through receptor-mediated endocytosis. ACE-2 is a membrane protein that serves many physiological functions in the lungs, heart, kidneys, and other organs. The mechanisms of cardiovascular injury from COVID-19 have not been fully elucidated and are likely multifactorial [2]. In addition, myocarditis is one concern among persons who received mRNAbased COVID-19 vaccines [3], [4]. In addition to its direct impact on the cardiovascular system, COVID-19 indirectly hinders the optimum treatment of CVDs by overwhelming the medical system [5], [6].
Meta-analysis showed that the prevalence of obesity, DM, hypertension, and CVD, along with commonly coexisting comorbidities/risk factors, was higher in patients with severe COVID-19 than those with mild-moderate COVID-19 [5]. This finding is similar both in the USA and China. A retrospective, single-center case series of 187 patients with COVID-19 found that patients with underlying CVD were more likely to have a cardiac injury with troponin ( $\mathrm{Tn}$ ) elevation compared with patients without CVD (54.5\% vs. 13.2\%) [2], this finding was supported by subsequent meta-analyses that showed cardiac injury and change in cardiac function in patients with COVID-19 [21], [22], [23], [24], [25], [26], [27].

A retrospective case series from Italy presented results from 1591 critically ill patients with COVID-19 admitted to the intensive care unit: $49 \%$ of patients had hypertension, $21 \%$ had CVD, and $17 \%$ had diabetes. In a study in New York between March 2, 2020, and April 1, 2020, 1150 adults with COVID-19 were admitted to two hospitals; 257 were critically ill. Of these, $82 \%$ had at least one chronic illness, the most common of which were hypertension $(63 \%)$, diabetes $(36 \%)$, obesity $(46 \%)$, and heart disease (19\%). In a large case series of 5700 patients with COVID-19 admitted to 12 hospitals in New York, the prevalence of hypertension, diabetes, and coronary artery disease was $57 \%, 34 \%$, and $11 \%$, respectively [28]. 
Reports from Italy showed that cardiovascular comorbidities were the most commonly associated with risk of death of COVID-19, most notably hypertension $(70 \%)$, ischemic heart disease $(30 \%)$, atrial fibrillation (20\%), and heart failure (15\%) [29].

\section{Acute COVID-19 Cardiovascular Syndrome}

COVID-19 can cause cardiovascular complications. It can be classified based on time infection:

a. Acute cardiac manifestations of SARS-CoV-2 infection (ACS, exacerbation of heart failure, myocarditis, cardiac arrhythmias, and their exacerbation) [30].

b. Post-acute COVID syndromes, in which symptoms beyond 4 weeks present during acute COVID or appearing later in the case of asymptomatic subjects. The symptoms are not the result of irreversible organic damage. Cardiac manifestations occur in patients with post-acute COVID syndrome such as arrhythmia and pericarditis. If recurrent palpitations (10-60\%) occur, the possibility of an inappropriate sinus tachycardia should be considered and a Postural Orthostatic Tachycardia Syndrome if it is associated with orthostatic symptoms. It is recommended in this case to include a Holter and a specific dysautonomia study [2], [3].

c. Long post-COVID syndromes, which are the symptoms associated with irreversible tissue damage after 12 weeks. Myocarditis and pericarditis can occur as cardiac manifestations in long post-COVID syndrome.

Definition of cardiac involvement in COVID19 is challenging, as SARS-CoV-2 infection has multifaceted effects, primary cardiac involvement, secondary cardiac involvement, and worsening of previous CVDs [31], Table 1.

Primary cardiac involvement may be the consequence of viral tropism for the endothelium and, presumably, the myocardium. A link between the respiratory syndrome and the pleomorphic cardiovascular manifestations associated with COVID19 could be identified in ACE-2, a membrane-bound enzyme that serves as the cell entry receptor for the SARS-CoV-2. ACE-2 is expressed in a variety of tissues, including lung alveolar epithelial cells and enterocytes of the small intestine, as well as arterial smooth muscle cells and endothelial cells [31].

Secondary cardiac involvement is the result of indirect myocardial damage during SARS-CoV-2 infection. Hyperinflammatory response in the advanced stage of the disease elicits cytokine storm, chiefly mediated by IL- 1 and IL- 6 pathways. These cytokines have been implicated in myocardial injury and adverse remodeling in clinical and experimental models of ACSs and may exhibit direct negative inotropic and metabolic effects on cardiomyocytes in sepsis-like settings. IL-1 plays a proven role in atherothrombosis and the resulting hyperinflammatory milieu may provoke atherosclerotic plaque instability and a procoagulant state with increased risk of arterial and venous acute thrombotic events, including type 1 myocardial infarction (MI) and pulmonary embolism (PE). Secondary cardiac involvement may also result from hypoxia-induced myocardial damage that could lead to type $2 \mathrm{Ml}$. This condition could either unmask underlying obstructive coronary artery disease or present as MI with non-obstructive coronary arteries [31].

Worsening of previously existing CVDs is frequently observed during COVID-19 and may explain the higher prevalence of patients with preexisting cardiovascular comorbidities in the nonsurvivor cohorts [31]. Several meta-analyses showed that CVD and severe COVID-19 are intertwined [21], [22],[23], [24],[25], [26], [32].

Table 1: Spectrum of acute COVID-19 cardiovascular syndrome [4]

\begin{tabular}{ll}
\hline Clinical presentation & Key manifestations \\
\hline Acute coronary & Chest pain, elevated troponin, wall motion \\
syndrome (STEMI or NSTEMI) & $\begin{array}{l}\text { abnormalities, and/or ST-segment depression or } \\
\text { elevation } \pm \text { T-wave abnormalities }\end{array}$ \\
Acute myocardial injury without & Elevated troponin \pm additional symptoms \\
obstructive CAD & \\
Arrhythmias & Atrial arrhythmias, ventricular tachycardia, ventricular \\
& fibrillation, or complete heart block \\
Heart failure \pm cardiogenic & De novo systolic dysfunction \\
shock & Myocarditis or myopericarditis \\
& Cytokine-mediated cardiomyopathy \\
& Stress-induced cardiomyopathy \\
& Mediated through other risk factors (e.g., atrial \\
& arrhythmias) \\
& Acute or chronic decompensated systolic dysfunction \pm \\
& elevated troponin \\
& Recurrent systolic dysfunction after LVEF recovery \\
& Heart failure with preserved LVEF \\
& \pm Tamponade (muffled heart sound, pulsus paradoxus, \\
& and elevated jugular venous pressure) \\
Pericardial effusion & Arterial thromboembolism, deep vein thrombosis, \\
& intracardiac thrombus, microvascular thrombi, \\
Thromboembolic complications & pulmonary embolism, stroke \\
\hline
\end{tabular}

\section{Pathogenesis Mechanism of Cardiovascular Complications in COVID-19}

\section{CRS and hemodynamic instability}

CRS, as a form of innate immune response, can also occur as a complication of viral infections and is responsible for acute respiratory distress syndrome (ARDS) and multiple organ failure. CRS represents dysregulated and excessive immune response that fails to defend the organism against the infection and damages the body. In their detailed review on CRS in SARS and 
COVID-19, they discussed that the respiratory epithelial cells, dendritic cells, and macrophages, after infection with SARS-CoV, first produce low levels of cytokines and chemokines, and in the later stages, these cells secrete low levels of the antiviral factors interferons and high levels of pro-inflammatory cytokines: IL-1 $\beta$, IL-6, and tumor necrosis factor, as well as the chemokines CCL-2, CCL-3, and CCL-5. The studies have shown that the level of IL- 6 correlates positively with the severity of the disease and the outcome, so the drugs that can inhibit secretion of IL-6 may have an important role in the treatment of CRS [33]. Meta-analysis showed that increased inflammatory markers such as IL-6, C-reactive protein, ferritin, and procalcitonin in patient with COVID19 were associated with increased COVID-19 severity and its associated mortality [34], [35], [36].

\section{Renin-angiotensin-aldosterone system (RAAS) system dysregulation}

COVID-19 enters host cells through ACE-2 distributed on pneumocytes type 2 and endothelial cells of the arteries, arterioles, and venules in various organs, including the lungs and the heart. ACE-2 functions as a negative regulator of the RAAS and has a role in the degradation of angiotensin- 2 , which results in the production of heptapeptide called angiotensin 1-7. Angiotensin 1-7 binds to G-protein-coupled oncogene receptors, exerting vasodilatation, antihypertrophic, and anti-inflammatory effects on the cardiovascular system. On the other side, angiotensin-2, as a part of RAAS, binds to its receptors - angiotensin- 2 receptors type 1 and causes vasoconstriction that leads to the rise of blood pressure. If overstimulated, angiotensin- 2 can negatively impact the cardiovascular system by causing hypertension, inflammation, myocardial fibrosis, and hypertrophy that eventually lead to heart failure. The loss of ACE-2 has been documented to negatively impact the cardiovascular system, leading to cardiac hypertrophy and contractility disorders. On the entrance throughACE-2 receptors, SARS-CoV-2 leads to the downregulation of these receptors [37], [38], [39]. This newly established imbalance between ACE-2 and angiotensin-2 may cause the appearance of cardiovascular complications in patients with no previous history of CVD or worsen the existing CVD in patients with COVID-19 [29].

\section{Plaque Destabilization}

As part of systemic inflammation, the increased level of catecholamines that were shown to occur in COVID-19 may lead to plaque rupture and destabilization, thus causing the ACS. Furthermore, the C-reactive protein levels were shown to directly correlate with the risk of the onset of MI due to plaque rupture [29].
The rupture of atheromatous plaque leads to the exposure of foamy macrophages located under the endothelium to the bloodstream. These macrophages express the tissue factor that initiates the formation of microthrombi in contact with the blood. Furthermore, the rupture of the plaque exposes vascular smooth muscle cells to the blood flow, which also expresses tissue factors that facilitate thrombogenesis [29]. The occurrence of stroke was also higher in patients with COVID-19, which might be due to plaque destabilization and prothrombotic state [40]. Statin, a well-known medication with pleiotropic properties, was shown to reduce mortality in patients with COVID-19 [41].

\section{Prothrombotic State and Coagulation Disorders}

The activation of coagulation during the systemic inflammation in COVID-19 can occur through several mechanisms. Polyphosphates derived from microorganisms activate platelets, mast cells, and factor XII of coagulation. Furthermore, the system of complement and components of neutrophil extracellular traps and the pathogen-associated molecular mechanisms are involved in the activation of the coagulation cascade. The procoagulant effects of hypoxemia should also be considered in the pathogenesis of coagulation disorders in COVID-19, bearing in mind that patients affected with this disease may develop a drop in oxygen saturation. The low oxygen levels activate the transcription factor early growth response-1 that leads to the transcription and translation of tissue factor in mononuclear phagocytes and smooth muscle cells, resulting in vascular fibrin deposition. Furthermore, hypoxia upregulates plasminogen activator inhibitor-1, which suppresses fibrinolysis. The induction of hypoxia-induced factors and endothelial inflammation during hypoxia and systemic inflammatory response may contribute to the formation of microthrombi [29]. Coagulopathy is one of the hallmarks of COVID-19, there is an alteration in several important parameters of platelet and coagulation function such as von Willebrand factor, d-dimer, and thromboplastin time [34], [35], [39], [42], [43]. Coagulopathy is hypothesized to be one of the most important complications, leading to mortality in patients with COVID-19 [39].

\section{Cardiovascular Manifestations in COVID-19}

\section{Myocarditis in COVID-19}

The prevalence of myocarditis among COVID-19 patients is unclear. Some argued that up 
to $7 \%$ of COVID-19-related deaths were attributable to myocarditis [44]. Intracellular SARS-CoV-2 might impair stress granule formation through its accessory protein. Without the stress granules, the virus is allowed to replicate and damage the cell. Naive T-lymphocytes can be primed for viral antigens through antigen-presenting cells and cardiac tropism by the heart-produced HGF. The HGF binds c-Met, an HGF receptor on T-lymphocytes. The primed CD8+ T-lymphocytes migrate to the cardiomyocytes and cause myocardial inflammation through cell-mediated cytotoxicity. In the cytokine storm syndrome, in which pro-inflammatory cytokines are released into the circulation, T-lymphocyte activation is augmented and releases more cytokines. This results in a positive feedback loop of immune activation and myocardial damage [44].

Clinical manifestations of myocarditis in COVID-19 vary among cases. Some patients may present with relatively mild symptoms, whereas others report chest pain or chest tightness on exertion. In severe cases, patients may also present with signs of right-sided heart failure. Myocarditis in COVID-19 also can cause arrhythmias [44]. Arrhythmia was highly prevalent in patients with COVID-19, as shown in a meta-analysis [24], Table 2.

The gold standard for diagnosing myocarditis is endomyocardial biopsy (EMB), but EMB is not routinely done. The American Heart Association (AHA) recommends further testing for patients having signs consistent with myocarditis with one or more cardiac imaging methods such as an echocardiogram or cardiovascular magnetic resonance. The echocardiogram usually is more readily deployed because it is portable. Results of blood tests from patients with myocarditis show elevated levels of lactate and other inflammatory markers such as C-reactive protein, erythrocyte sedimentation rate, and procalcitonin. In myocarditis, patients should be tested with baseline cardiac enzymes (e.g., Th and NT-proBNP) on hospital admission. Cardiac enzyme levels usually are elevated in COVID-19-related myocarditis [44], [45].

Table 2: Cardiovascular involvement during COVID-19 [5]

\begin{tabular}{|c|c|}
\hline Pathogenetic mechanism & Clinical manifestations \\
\hline Primary cardiac involvement & \\
\hline Direct viral damage (hypothesized) & Viral myocarditis \\
\hline Secondary cardiac involvement & \\
\hline Cytokine storm & Inflammatory myocarditis \\
\hline Oxygen supply demand imbalance & Type $2 \mathrm{MI}$ \\
\hline $\begin{array}{l}\text { Inflammatory prothrombotic state atherosclerotic plaque } \\
\text { instabilization }\end{array}$ & Type $1 \mathrm{Ml}$ \\
\hline Inflammatory prothrombotic state & VTE and acute PE \\
\hline Lung inflammation & $\mathrm{RV}$ increased afterload \\
\hline Hypoxic vasoconstriction & \\
\hline High PEEP mechanical ventilation & \\
\hline $\begin{array}{l}\text { Pulmonary thromboembolism } \\
\text { Worsening pre-existing conditions }\end{array}$ & \\
\hline Infection-related metabolic demand & Heart failure exacerbation \\
\hline Cytokine storm & \\
\hline Hypoxia & Arrhythmias \\
\hline Cytokine storm & \\
\hline $\begin{array}{l}\text { Drugs side effects (QT prolongation: Hydroxychloroquine and } \\
\text { azithromycin alone or in combination with AADs) }\end{array}$ & \\
\hline
\end{tabular}

\section{Heart failure}

Heart failure has been well described in patients with pneumonia and now there is an association between heart failure and COVID-19 [46]. Patients with COVID-19 may develop right-sided heart failure secondary to pulmonary hypertension due to hypoxia and ARDS [28].

The etiology of heart failure related to COVID-19 infection is unclear, it can be caused by the direct effect of SARS-CoV-2 on the myocardium and indirectly caused by hypoxia, cytokine release, volume overload, renal failure, stress, or overwhelming critical illness. Some patients with risk factors (diabetes, hypertension, hyperlipidemia, and coronary artery disease) may have had underlying subclinical heart failure uncovered or exacerbated by COVID-19 infection and associated illness [28].

Diagnostic workup for suspected heart failure includes brain natriuretic peptide, Tn markers, transthoracic echocardiography, and cardiac MRI in COVID-19 patients with diastolic heart failure [28]. Patients with heart failure may need cardiopulmonary support, which may signify a poor prognosis [47].

\section{ACS}

There is an association between COVID19 and ACS in several studies and case reports. Investigators from New York reported their experience with COVID-19 with ST-segment elevation on ECG. In Italy, researchers published a study of 28 patients with confirmed COVID-19 who had undergone coronary angiogram for ST-elevation MI [28].

The pathophysiology of ACS in COVID-19 is not clear, but it may be related to direct endothelial injury by the SARS-CoV-2 virus, microthrombi formation, or systemic inflammation and cytokine storm resulting in plaque rupture or coronary spasm [28].

\section{Thromboembolism and coagulation abnormalities}

The hypercoagulable state in COVID-19 infection is related to severe inflammatory response, cytokine storm, and endothelial damage, along with underlying patients with comorbidities. Studies in patients with COVID-19 have shown abnormalities of the coagulation cascade, with elevated D-dimer, thrombocytopenia, slightly elevated prothrombin time, and higher levels of fibrinogen and von Willebrand factor. In a retrospective cohort study from China, elevated D-dimer was associated with poor prognosis and a higher risk of mortality [28]. Metaanalysis showed that changes in von Willebrand factor level, d-dimer, and thromboplastin time were strongly associated with mortality in patients with COVID-19 [34], [35], [39], [42], [43]. 
The incidence of acute ischemic stroke in patients with COVID-19 is approximately $1-3 \%$. Peripheral arterial thromboembolism causing acute limb ischemia also has been described in COVID19 patients with or without risk factors [28].

There is increasing evidence that anticoagulation is of benefit in COVID-19 illness [28]. Aspirin, which inhibits platelet function, was shown to reduce mortality in patients with COVID-19 [48].

\section{COVID-19 treatments and its effect on cardiovascular system}

Early during the pandemic, chloroquine and hydroxychloroquine were suggested to have clinical benefit in patients with COVID-19 and were widely used. Chloroquine and hydroxychloroquine are proarrhythmic and cause significant QT prolongation and increase the risk of Torsade de Pointes (TdP) even at therapeutic doses. The AHA has listed chloroquine and hydroxychloroquine as agents which can cause direct myocardial toxicity and exacerbate underlying myocardial dysfunction [49], Table 3.

Antiviral drugs, such as lopinavir/ritonavir, can cause QT prolongation and are CYP3A4 inhibitors. Prolonged QT interval due to favipiravir has been reported. Darunavir/ritonavir is a major CYP3A4 inhibitor. Remdesivir and its effect on cardiovascular are unknown, initial data indicate that remdesivir may be associated with hypotension [49], [50].

Tocilizumab and sarilumab are IL-6 inhibitors. Both drugs are not associated with heart failure exacerbation or pro-arrhythmia. Tocilizumab was used safely among patients with autoimmune disease and cardiomyopathy [49].

Table 3: Management of cardiovascular complications in COVID-19 patients [1]

\begin{tabular}{|c|c|}
\hline & Therapy \\
\hline STEMI and NSTEMI & Primary $\mathrm{PCl}$ or thrombolytics \\
\hline Myocardial injury & Worse prognosis, monitoring rising trends \\
\hline Hypercoagulable state & Thromboprophylaxis \\
\hline Ace or ARB use & Continue treatment, currently await further studies \\
\hline $\begin{array}{l}\mathrm{HCQ}, \mathrm{CQ} \text {, and/or } \\
\text { azithromycin use }\end{array}$ & Qtc monitoring, avoid other Qtc prolonging drugs \\
\hline $\begin{array}{l}\text { Immunosuppression/ } \\
\text { immunomodulation }\end{array}$ & May be helpful in selected patients with cytokine storm \\
\hline $\begin{array}{l}\text { Mechanical circulatory } \\
\text { support }\end{array}$ & $\begin{array}{l}\text { IABP and venoarterial ECMO might be used for support in } \\
\text { cardiogenic shock }\end{array}$ \\
\hline
\end{tabular}
hydroxychloroquine or antiviral drugs with other antibiotics must be careful. QT interval monitoring should be performed when concomitant macrolide drugs (such as azithromycin and moxifloxacin) are administered. Piperacillin-tazobactam carries some risk of TdP, especially when one of the additional risks or TdP presents (bradycardia, hypokalemia, hypomagnesemia, use with concomitant QT/TdP drugs, and use with drugs that can cause hypokalemia or hypomagnesemia) [49].

\section{COVID-19 vaccination in patients with CVD}

COVID-19 vaccination does not prevent people from catching the COVID-19 infection, but it will reduce serious illnesses that may require hospital admission and death. People with CVD may be at increased risk of dying from COVID-19 because the infection causes myocardial inflammation. Therefore, COVID-19 vaccination is essential in patients with cardiovascular comorbidities.

There are two reports in the current issues of JAMA Cardiology describing cases of acute myocarditis that occurred among persons who received mRNA-based COVID-19 vaccines. The first report describes four cases of myocarditis with symptom onset 1-5 days after receipt of the second dose of mRNA-based COVID-19 vaccine (two receiving the BNT162b2-mRNA vaccine and two receiving the mRNA-1273 vaccine) who were evaluated in a single tertiary care medical center (Duke University Medical Center). The second, more extensive case report comes from the US Military Health System and describes 23 individuals with acute myocarditis who presented within 4 days after mRNA-based COVID19 vaccination. The precise mechanism by which immunologic responses to mRNA-based COVID-19 vaccines could lead to myocarditis is still unclear. Further investigation is critical and should be informed that most cases occurred following the second dose of a 2-dose series, some in patients with a history of prior COVID-19 infection [51].

The current recommendation of the Indonesian Heart Association stated that patients with CVD such as ACS, acute heart failure, and unstable arrhythmia can have COVID-19 vaccination after 2-4 weeks after the acute phase. Patients with the stable cardiovascular condition after PCl/CABG, ablation procedure, implantation of ICD, or other elective procedure can have vaccination 1-2 weeks after the procedure. COVID-19 vaccines are generally safe in stable patients with hypertension with blood pressure $<180 / 100 \mathrm{mmHg}$. Sinovac and Pfizer vaccines can be given to young people (12-17 years old) with congenital and rheumatic heart diseases. Patients with CVD and in stable condition can get mRNA-based COVID-19 vaccine. Myocarditis/pericarditis, caused by mRNAbased COVID-19 vaccine, is still under investigation. Incidence of myocarditis related to COVID-19 vaccination $(0.00126 \%)$ is smaller than myocarditis related to COVID-19 infection (2.3\%) [51].

\section{Conclusion}

COVID-19 patients with CVD have higher mortality, and the severity of COVID-19 disease correlates with cardiovascular manifestations. 
Cardiovascular manifestations related to COVID-19 infection are myocarditis, myocardial injury, elevated liver enzymes, heart failure, ACS, arrhythmias, thromboembolism, and coagulation abnormalities. Furthermore, COVID-19 treatments can affect the cardiovascular system, such as QT prolongation. Nevertheless, COVID-19 vaccination is relatively safe for patients with cardiovascular comorbidities.

\section{References}

1. Mahalmani VM, Mahendru D, Semwal A, Kaur S, Kaur H, Sarma P, et al. COVID-19 pandemic: A review based on current evidence. Indian J Pharmacol. 2020;52(2):117-29. https://doi. org/10.4103/ijp.ijp_310_20

PMid:32565599

2. Kang Y, Chen T, Mui D, Ferrari V, Jagasia D, Scherrer-Crosbie M, Chen $\mathrm{Y}$, et al. Cardiovascular manifestations and treatment considerations in COVID-19. Heart. 2020;106(15):1132-41. https://doi.org/10.1136/heartjnl-2020-317056 PMid:32354800

3. Abu Mouch S, Roguin A, Hellou E, Ishai A, Shoshan U, Mahamid L, et al. Myocarditis following COVID-19 mRNA vaccination. Vaccine. 2021;39(29):3790-3. https://doi. org/10.1016/j.vaccine.2021.05.087 PMid:34092429

4. Bozkurt B, Kamat I, Hotez PJ. Myocarditis with COVID-19 mRNA Vaccines. Circulation. 2021;144(6):471-84. https://doi. org/10.1161/circulationaha.121.056135 PMid:34281357

5. Lim MA, Huang I, Yonas E, Vania R, Pranata R. A wave of noncommunicable diseases following the COVID-19 pandemic. Diabetes Metab Syndr Clin Res Rev. 2020;14(5):979-80. https:// doi.org/10.1016/j.dsx.2020.06.050 PMid:32610263

6. Pranata R, Lim MA, Yonas E, Siswanto BB, Meyer M. Outof-hospital cardiac arrest prognosis during the COVID-19 pandemic. Intern Emerg Med. 2020;15(5):875-7. https://doi. org/10.1007/s11739-020-02428-7

PMid:32647947

7. Pranata R, Huang I, Lim MA, Wahjoepramono EJ, July J. Impact of cerebrovascular and cardiovascular diseases on mortality and severity of COVID-19-systematic review, meta-analysis, and meta-regression. J Stroke Cerebrovasc Dis. 2020;29(8):104949. https://doi.org/10.1016/j.jstrokecerebrovasdis.2020.104949 PMid:32410807

8. Pranata R, Lim MA, Yonas E, Vania R, Lukito AA, et al. Body mass index and outcome in patients with COVID-19: A doseresponse meta-analysis. Diabetes Metab. 2021;47:101178. https://doi.org/10.1016/j.diabet.2020.07.005

9. Pranata R, Lim MA, Huang I, Raharjo SB, Lukito AA Hypertension is associated with increased mortality and severity of disease in COVID-19 pneumonia: A systematic review, meta-analysis and meta-regression. J Renin-Angiotensin Aldosterone Syst. 2020;21:147032032092689. https://doi. org/10.1177/1470320320926899 PMid:32408793

10. Pranata R, Henrina J, Raffaello WM, Lawrensia S, Huang I. Diabetes and COVID-19: The past, the present, and the future. Metabolism. 2021;121:154814. https://doi.org/10.1016/j.

\section{metabol.2021.154814}

PMid:34119537

11. Pranata R, Supriyadi R, Huang I, Permana H, Lim MA et al. The association between chronic kidney disease and new onset renal replacement therapy on the outcome of COVID-19 patients: A meta-analysis. Clin Med Insights Circ Respir Pulm Med. 2020;14:1179548420959165. https://doi. org/10.1177/1179548420959165 PMid:32994700

12. Huang I, Lim MA, Pranata R. Diabetes mellitus is associated with increased mortality and severity of disease in COVID-19 pneumonia a systematic review, meta-analysis, and metaregression: Diabetes and COVID-19. Diabetes Metab Syndr Clin Res Rev. 2020;14(4):395-403. https://doi.org/10.1016/j. dsx.2020.04.018

PMid:32334395

13. Pranata R, Henrina J, Lim MA, Lawrensia S, Yonas E, Vania R, et al. Clinical frailty scale and mortality in COVID-19: A systematic review and dose-response meta-analysis: Clinical frailty scale in COVID-19. Arch Gerontol Geriatr. 2021;93:104324. https://doi. org/10.1016/j.archger.2020.104324

PMid:33352430

14. Pranata R, Huang I, Lim MA, Yonas E, Vania R, et al. Delirium and mortality in coronavirus disease 2019 (COVID-19) a systematic review and meta-analysis. Arch Gerontol Geriatr. 2021;95:104388. https://doi.org/10.1016/j.archger.2021.104388

15. July J, Pranata R. Prevalence of dementia and its impact on mortality in patients with coronavirus disease 2019: A systematic review and meta-analysis. Geriatr Gerontol Int. 2021;21:172-7. https://doi.org/10.1111/ggi.14107

PMid:33340212

16. Pranata R, Lim MA, Huang I, Yonas E, Henrina J, Vania R, et al. Visceral adiposity, subcutaneous adiposity, and severe coronavirus disease-2019 (COVID-19): Systematic review and meta-analysis. Clin Nutr ESPEN. 2021;43:163-8. https://doi. org/10.1016/j.clnesp.2021.04.001

PMid:34024509

17. Akbar MR, Wibowo A, Pranata R, Setiabudiawan B. Low serum 25-hydroxyvitamin $D$ (Vitamin $D$ ) level is associated with susceptibility to COVID-19, severity, and mortality: A systematic review and meta-analysis. Front Nutr. 201;8:660420. https://doi. org/10.3389/fnut.2021.660420

PMid:33855042

18. Pranata R, Soeroto AY, Huang I, Lim MA, Santoso P, Permana H, et al. Effect of chronic obstructive pulmonary disease and smoking on the outcome of COVID-19. Int J Tuberc Lung Dis. 2020;24(8):838-43. https://doi.org/10.5588/ijtld.20.0278 PMid:32912389

19. Kuswardhani RA, Henrina J, Pranata R, Lim MA, Lawrensia S, Suastika K. Charlson comorbidity index and a composite of poor outcomes in COVID-19 patients: A systematic review and metaanalysis. Diabetes Metab Syndr Clin Res Rev. 2020;14:2103-9. https://doi.org/10.1016/j.dsx.2020.10.022 PMid:33161221

20. Lim MA, Pranata R. The Danger of sedentary lifestyle in diabetic and obese people during the COVID-19 pandemic. Clin Med Insights Endocrinol Diabetes. 2020;13:1179551420964487. https://doi.org/10.1177/1179551420964487 PMid:33149717

21. Pranata R, Huang I, Raharjo SB. Incidence and impact of cardiac arrhythmias in coronavirus disease 2019 (COVID19): A systematic review and meta-analysis. Indian Pacing Electrophysiol J. 2020;20:193-8. https://doi.org/10.1016/j. ipej.2020.08.001

PMid:32814094 
22. Wibowo A, Pranata R, Astuti A, Tiksnadi BB, Martanto E, et al. Left and right ventricular longitudinal strains are associated with poor outcome in COVID-19: A systematic review and metaanalysis. J Intensive Care. 2021;9(1):9. https://doi.org/10.1186/ s40560-020-00519-3

PMid:33436101

23. Santoso A, Pranata R, Wibowo A, Al-Farabi MJ, Huang I, Antariksa B. Cardiac injury is associated with mortality and critically ill pneumonia in COVID-19: A meta-analysis. Am J Emerg Med. 2021;44:352-7. https://doi.org/10.1016/j. ajem.2020.04.052

PMid:32331955

24. Martha JW, Pranata R, Wibowo A, Lim MA. Tricuspid annular plane systolic excursion (TAPSE) measured by echocardiography and mortality in COVID-19: A systematic review and meta-analysis. Int J Infect Dis. 2021;105:351-6. https://doi.org/10.1016/j.ijid.2021.02.029

PMid:33582370

25. Pranata R, Huang I, Lukito AA, Raharjo SB. Elevated N-Terminal pro-brain natriuretic peptide is associated with increased mortality in patients with COVID-19: Systematic review and meta-Analysis. Postgrad Med J. 2020;96(1137):387-91. https:// doi.org/10.1136/postgradmedj-2020-137884

PMid:32434874

26. Akbar MR, Pranata R, Wibowo A, Lim MA, Sihite TA, Martha JW. The prognostic value of elevated creatine kinase to predict poor outcome in patients with COVID-19 a systematic review and meta-analysis: Creatinine Kinase in COVID-19. Diabetes Metab Syndr Clin Res Rev. 2021;15(2):529-34.

PMid:33668003

27. Wibowo A, Pranata R, Akbar MR, Purnomowati A, Martha JW. Prognostic performance of troponin in COVID-19: A diagnostic meta-analysis and meta-regression. Int $\mathrm{J}$ Infect Dis. 2021;105:312-8. https://doi.org/10.1016/j.ijid.2021.02.113 PMid:33667694

28. Basu-Ray I, Almaddah NK, Adeboye A, Soos MP. Cardiac Manifestations Of Coronavirus (COVID-19). Treasure Island, FL: StatPearls; 2021.

29. Petrovic V, Radenkovic D, Radenkovic G, Djordjevic V, Banach M. Pathophysiology of cardiovascular complications in COVID-19. Front Physiol. 2020;11:575600. https://doi. org/10.3389/fphys.2020.575600

PMid:33162899

30. Filipiak KJ. COVID-19 complications new types of cardiovascular disease in 2021? A few comments on: COVID-19, post-COVID syndrome and the LONG COVID syndrome. Folia Cardiol. 2021;16:71-3.

31. Agricola E, Beneduce A, Esposito A, Ingallina G, Palumbo D, Palmisano $A$, et al. Heart and lung multimodality imaging in COVID-19. JACC Cardiovasc Imaging. 2020;13(8):1792-808. https://doi.org/10.1016/j.jcmg.2020.05.017 PMid:32762885

32. Hulot JS. COVID-19 in patients with cardiovascular diseases. Arch Cardiovasc Dis. 2020;113(4):225-6. http://doi. org/10.1016/j.acvd.2020.03.009 PMid:32245656

33. Yonas E, Alwi I, Pranata R, Huang I, Lim MA, Yamin M, et al. Elevated interleukin levels are associated with higher severity and mortality in COVID 19 a systematic review, meta-analysis, and meta-regression. Diabetes Metab Syndr Clin Res Rev. 2020;14(6):2219-30. https://doi.org/10.1016/j.dsx.2020.11.011 PMid:33395783

34. Huang I, Pranata R, Lim MA, Oehadian A, Alisjahbana B. C-reactive protein, procalcitonin, D-dimer, and ferritin in severe coronavirus disease-2019: A meta-analysis. Ther
Adv Respir Dis. 2020;4:1753466620937175. https://doi. org/10.1177/1753466620937175

PMid:32615866

35. Pranata R, Yonas E, Huang I, Lim MA, Nasution SA, Aman S, et al. Fibrosis-4 index and mortality in coronavirus disease 2019. Eur J Gastroenterol Hepatol. 2021;19:2091. https://doi. org/10.1097/meg.0000000000002091.

36. Udomsinprasert W, Jittikoon J, Sangroongruangsri S. Circulating levels of interleukin-6 and interleukin-10, but not tumor necrosis factor-alpha, as potential biomarkers of severity and mortality for COVID-19: Systematic review with meta-analysis. J Clin Immunol. 2021;41(1):11-22. http://doi.org/10.1007/ s10875-020-00899-z

PMid:33128665

37. Pranata R, Permana H, Huang I, Lim MA, Soetedjo NN, Supriyadi $R$, et al. The use of renin angiotensin system inhibitor on mortality in patients with coronavirus disease 2019 (COVID19): A systematic review and meta-analysis. Diabetes Metab Syndr Clin Res Rev. 2020;14(5):983-90.

38. Lukito AA, Pranata R, Henrina J, Lim MA, Lawrensia S, Suastika K. The effect of metformin consumption on mortality in hospitalized COVID-19 patients: A systematic review and metaanalysis. Diabetes Metab Syndr Clin Res Rev. 2020;14(6):217783. https://doi.org/10.1016/j.dsx.2020.11.006 PMid:33395778

39. Lim MA, Pranata R, Huang I, Yonas E, Soeroto AY, Supriyadi R. Multiorgan failure with emphasis on acute kidney injury and severity of COVID-19: Systematic review and meta-analysis. Can J Kidney Health Dis. 2020;7:2054358120938573. https:// doi.org/10.1177/2054358120938573

PMid:32685180

40. July J, Pranata R. Impact of the coronavirus disease pandemic on the number of strokes and mechanical thrombectomies: A systematic review and meta-analysis. J Stroke Cerebrovasc Dis. 2020;29(11):105185. https://doi.org/10.1016/j. jstrokecerebrovasdis.2020.105185

41. Zein AF, Sulistiyana CS, Khasanah U, Wibowo A, Lim MA, Pranata R. Statin and mortality in COVID-19: A systematic review and meta-analysis of pooled adjusted effect estimates from propensity-matched cohorts. Postgrad Med J. 2021;2021:140409. 10.1136/postgradmedj-2021-140409 PMid:34193549

42. Pranata R, Lim MA, Yonas E, Huang I, Nasution SA Setiati $\mathrm{S}$, et al. Thrombocytopenia as a prognostic marker in COVID-19 patients: Diagnostic test accuracy meta-analysis. Epidemiol Infect. 2021;149:e40. https://doi.org/10.1017/ S0950268821000236

PMid:33509306

43. Wibowo A, Pranata R, Lim MA, Akbar MR, Martha JW. Endotheliopathy marked by high von willebrand factor (VWF) antigen in COVID-19 is associated with poor outcome: A systematic review and meta-analysis. Int J Infect Dis. 2021;2021:540. https://doi.org/10.1016/j.jij.2021.06.051. PMid:34192577

44. Siripanthong B, Nazarian S, Muser D, Deo R, Santangeli $P$, Khanji M, et al. Recognizing COVID-19-related myocarditis: The possible pathophysiology and proposed guideline for diagnosis and management. Hear Rhythm. 2020;17:1463-71. https://doi. org/10.1016/j.hrthm.2020.05.001

PMid:32387246

45. Caforio AL, Pankuweit S, Arbustini E, Basso C, GimenoBlanes J, Felix SB, et al. Current state of knowledge on aetiology, diagnosis, management, and therapy of myocarditis: A position statement of the European society of cardiology working group on myocardial and pericardial diseases. Eur Heart J. 2013;34(33):2636-48. https://doi.org/10.1093/eurheartj/eht210 


\section{PMid:23824828}

46. Yonas E, Alwi I, Pranata R, Huang I, Lim MA, Gutierrez EJ, et al. Effect of heart failure on the outcome of COVID-19 a meta analysis and systematic review. Am J Emerg Med. 2021;46:20411. https://doi.org/10.1016/j.ajem.2020.07.009.

47. Raffaello WM, Huang I, Siswanto BB, Pranata R. In-depth review of cardiopulmonary support in COVID-19 patients with heart failure. World J Cardiol. 2021;13(8):298-308. https://doi. org/10.4330/wjc.v13.i8.298

\section{PMid:34589166}

48. Martha JW, Pranata R, Lim MA, Wibowo A, Akbar MR. Active prescription of low-dose aspirin during or prior to hospitalization and mortality in COVID-19: A systematic review and metaanalysis of adjusted effect estimates. Int J Infect Dis. 2021;108:612. https://doi.org/10.1016/j.ijid.2021.05.016

Author Query???

AQ4: $\quad$ Please note some reference (6-20) are not cited in text part

\section{PMid:34000418}

49. Naksuk N, Lazar S, Peeraphatdit TB. Cardiac safety of off-labe COVID-19 drug therapy: A review and proposed monitoring protocol. Eur Hear journal Acute Cardiovasc Care. 2020;9(3):21521. DOI: https://doi.org/10.1177/2048872620922784 PMid:32372695

50. Birkhoelzer SM, Cowan E, Guha K. COVID-19: Treatments and the potential for cardiotoxicity. Br J Cardiol. 2021;28:7-10. https://doi.org/10.5837/bjc.2021.007

51. Montgomery J, Ryan M, Engler R, Hoffman D, McClenathan B, Collins $\mathrm{L}$, et al. Myocarditis following immunization with mRNA COVID-19 vaccines in members of the US military. JAMA Cardiol. 2021;29:e212833. https://doi.org/10.1001/ jamacardio.2021.2833

PMid:34185045 